\title{
PENGARUH ANTARA GAYA PEMBELAJARAN MURID DAN PENGGUNAAN SUMBER-SUMBER SEJARAH
}

\section{THE RELATIONSHIP BETWEEN STUDENT'S LEARNING STYLES AND USING HISTORICAL SOURCES}

\author{
M. Kaviza \\ Pusat Pengajian Pendidikan dan Bahasa Moden, Universiti Utara Malaysia. \\ (Email: kavizakaviza@yahoo.com)
}

Received date: 14-05-2019

Revised date: 17-05-2019

Accepted date: 21-07-2019

Published date: 15-09-2019

To cite this document: Kaviza. M. (2019). Pengaruh Antara Gaya Pembelajaran Murid Dan Penggunaan Sumber-Sumber Sejarah. International Journal of Education, Psychology and Counseling, 4 (32), 130-138.

DOI: $10.35631 /$ IJEPC.4320013

\begin{abstract}
Abstrak: Kajian berbentuk tinjauan secara korelasi ini adalah bertujuan untuk menentukan sama ada gaya pembelajaran murid mempunyai hubungan terhadap penggunaan sumbersumber sejarah. Seramai 521 orang murid Tingkatan Empat terlibat dalam kajian ini. Instrumen kajian ini merupakan soal selidik yang telah diadaptasi, disahkan pakar dan mempunyai nilai kebolehpercayaan yang baik. Data kajian ini telah dianalisis secara statistik inferensi iaitu ujian korelasi Pearson dan ujian regresi pelbagai melalui perisian IBM SPSS. Dapatan kajian ini menunjukkan bahawa terdapat hubungan linear positif yang amat tinggi yang signifikan antara gaya pembelajaran dengan penggunaan sumber-sumber sejarah dari aspek pengetahuan, kemahiran dan sikap. Tambahan pula, gaya berkumpulan, gaya visual, gaya bersendirian dan gaya auditori didapati menyumbang kepada penggunaan sumbersumber sejarah secara signifikan. Implikasi kajian ini telah mencadangkan bahawa penggunaan sumber-sumber sejarah perlu diterapkan secara menyeluruh dalam proses pengajaran dan pembelajaran sejarah dengan mengambil kira aspek gaya pembelajaran murid.
\end{abstract}

Kata Kunci: Gaya Pembelajaran, Sumber-Sumber Sejarah, Murid Tingkatan Empat, Korelasi

Abstract: This correlation survey is aimed at determine whether student learning styles have relationship towards the use of historical sources. A total of 521 form four students were involved in this study. This adapted which have been validated by experts and has good reliability value are the instrument of this study. The data were analysed by inferred statistic such as Pearson Correlation and Multiple Regression test using IBM SPSS Software. The findings showed that there is a very high positive linear significant correlation between the learning style and the use of historical sources in terms of knowledge, skills and attitudes. Furthermore, grouping styles, visual styles, individual styles and auditory styles are found 
significantly contribute towards the use of historical sources. The implication of this study has suggested that the use of historical resources should be fully applied in the process of history teaching and learning by focusing of student learning styles.

Keywords: Student Learning, Historical Sources, Form Four Students, Correlation

\section{Pendahuluan}

Bagi mencapai matlamat kurikulum sejarah iaitu untuk mewujudkan semangat perpaduan dan kekitaan bangsa dan negara Malaysia (Pusat Perkembangan Kurikulum [PPK], 2003), maka murid-murid perlu memahami keadaan masyarakat dan negara dan hubungannya dengan sejarah dunia. Adalah diakui bahawa matlamat kurikulum yang digariskan tersebut hanya dapat dicapai apabila murid-murid didedahkan dengan penggunaan sumber-sumber sejarah dalam proses pengajaran dan pembelajaran sejarah yang berpotensi dapat merangsang kefahaman dan keintektualan murid dengan meneroka bahan-bahan bukti sejarah yang lama (Johansson, 2017; Hover, Hicks, \& Dack, 2016). Penggunaan sumber-sumber sejarah seperti sumber bertulis, sumber artifak, sumber visual, sumber lisan dan sebagainya (Lee, Doolittle \& Hicks, 2006; Hazri Jamil, 2003) dalam proses pengajaran dan pembelajaran sejarah telah dibuktikan memberikan kesan positif terhadap peningkatan kefahaman dan pemikiran analitikal (Patterson, Lucas \& Kithinji, 2012; Wiley \& Voss, 1999). Hal ini kerana muridmurid dapat membentuk persekitaran pembelajaran yang bermakna melalui penerokaan sumber-sumber sejarah sebagai bahan pengajaran dan pembelajaran bagi menjana proses kefahaman sejarah dengan menggalakkan mereka untuk memainkan peranan sebagai seorang pakar pengkaji sejarah (Greene, 1994; Wineburg, 1991). Kini, penggunaan sumber-sumber sejarah telah mula diberi perhatian dalam pendidikan sejarah dengan mempratikkannya sebagai bahan pengajaran dan pembelajaran yang dapat membekalkan maklumat-maklumat sejarah bagi memperincikan sesuatu peristiwa sejarah yang telah lepas (Reisman \& Fogo, 2016; Dutt-Doner, Cook-Cottone \& Alien, 2007).

\section{Pernyataan Masalah}

Sungguhpun begitu, tahap pengetahuan, kemahiran dan sikap murid terhadap penggunaan sumber-sumber sejarah yang didapati masih berada pada tahap sederhana (Kaviza, 2018a) telah menimbulkan satu persoalan sama ada gaya pembelajaran yang berbeza yang diamalkan oleh murid di dalam proses pengajaran dan pembelajaran sejarah mempengaruhi tahap penggunaan sumber-sumber sejarah tersebut. Hal ini kerana setiap murid mempunyai cara dan kadar belajar yang berbeza yang menyebabkan mereka bertindak balas dari aspek stail berfikir, pengalaman lepas, persekitaran pembelajaran, bahan-bahan pengajaran dan tugasantugasan pembelajaran (Suppiah Nachiappan, Kamarulzaman Kamaruddin, Abdul Aziz Abdul Shukor, Ramlah Jantan, Roslinda Mustapha \& Hazalizah Hamzah, 2009). Walaubagaimanapun, aspek gaya pembelajaran perlu dipertimbangkan oleh guru-guru sejarah terlebih dahulu sebelum sesuatu proses pengajaran dan pembelajaran dirancang dan dilaksanakan di dalam kelas. Pendapat ini adalah konsisten dengan saranan Curry, (1983) yang menjelaskan bahawa sekiranya pendekatan, kaedah, dan teknik pengajaran yang diperkenalkan kepada murid adalah tidak sepadan dengan gaya pembelajaran seseorang murid, maka murid tersebut mungkin berhenti untuk belajar walaupun mereka terlibat dan berada dalam proses pengajaran dan pembelajaran tersebut. Tambahan pula, pendapat McLaughlin, (1999) juga telah menjelaskan gaya pembelajaran sebagai persepsi kognitif iaitu bagaimana murid memproses dan mempersembahkan maklumat mempunyai kaitan dengan 
keberkesanan proses pengajaran dan pembelajaran yang telah menimbulkan keperluan untuk menentukan sama ada gaya pembelajaran mempunyai hubungan dengan penggunaan sumbersumber sejarah yang dikonsepsikan sebagai kaedah pengajaran dan pembelajaran sejarah walaupun dalam satu kajian tinjauan awal yang dijalankan oleh pengkaji telah mendapati bahawa gaya auditori dan gaya berkumpulan merupakan gaya pembelajaran yang utama diamalkan oleh murid-murid Tingkatan Empat yang mengambil mata pelajaran sejarah di sekolah menengah harian (Kaviza, 2019).

\section{Objektif Kajian}

Objektif kajian ini ialah:

1. Menentukan sama ada gaya pembelajaran mempunyai hubungan yang signifikan terhadap penggunaan sumber-sumber sejarah dari aspek pengetahuan, kemahiran dan sikap

2. Menentukan sama ada gaya visual, gaya auditori, gaya taktil, gaya kinestetik, gaya bersendirian dan gaya berkumpulan merupakan pembolehubah peramal secara signifikan yang mempengaruhi penggunaan sumber-sumber sejarah

\section{Metodologi Kajian}

Kajian ini dijalankan secara tinjauan dengan reka bentuk kajian korelasi (Cresswell, 2014) yang melibatkan seramai 521 orang murid Tingkatan Empat yang dipilih melalui teknik persampelan rawak mudah di sebuah negeri di utara Semenanjung Malaysia. Rasional pengkaji memilih murid Tingkatan Empat dalam kajian ini adalah berdasarkan keperluan murid menjalankan kajian sejarah dalam Kertas Tiga dalam format peperiksaan Sijil Pelajaran Malaysia (SPM). Instrumen kajian ini merupakan soal selidik penggunaan sumber-sumber sejarah dan Perceptual Learning Style Preferences Questionnaire (Reid, 1984) yang telah diadaptasi, disahkan oleh pakar penilai dan mempunyai nilai kebolehpercayaan yang diterima bagi tujuan kajian ini (Nunnally, 1978). Data kajian ini dianalisis secara inferensi iaitu ujian korelasi Pearson dan ujian Regresi Pelbagai melalui perisian IBM SPSS. Interpretasi kekuatan korelasi dalam kajian ini dilakukan berdasarkan adaptasi interpretasi daripada kajian Davies, (1971) pada Jadual 1.

\section{Jadual 1: Interpretasi Kekuatan Korelasi}

\begin{tabular}{cc}
\hline Skor Min & Tahap \\
\hline $0.70-1.00$ & Amat tinggi \\
$0.50-0.69$ & Tinggi \\
$0.30-0.49$ & Sederhana tiggi \\
$0.10-0.29$ & Rendah \\
$0.00-0.09$ & Diabaikan \\
\hline
\end{tabular}

Sumber: Adaptasi daripada Davies, (1971)

\section{Dapatan Kajian}

\section{Soalan Kajian 1}

Terdapat Hubungan yang Signifikan Antara Gaya Pembelajaran dengan Penggunaan Sumber-Sumber Sejarah

Berdasarkan Jadual 2, dapatan kajian ini telah melaporkan bahawa nilai keofisien korelasi Pearson antara min gaya pembelajaran $[r=0.82, p=0.00]$ terhadap penggunaan sumber-sumber sejarah adalah signifikan. Oleh itu, terdapat hubungan linear positif yang amat tinggi secara 
signifikan antara min gaya pembelajaran terhadap penggunaan sumber-sumber sejarah. Maka, $\mathrm{H}_{01}$ telah berjaya ditolak. Justeru, terdapat hubungan yang signifikan antara min gaya pembelajaran terhadap penggunaan sumber-sumber sejarah dalam kalangan murid. Perkara ini menerangkan bahawa sekiranya kecenderungan gaya pembelajaran adalah tinggi dalam kalangan murid, maka penggunaan sumber-sumber sejarah dalam kalangan murid juga adalah tinggi.

Jadual 2: Korelasi Gaya Pembelajaran dengan Penggunaan Sumber-Sumber Sejarah

\begin{tabular}{llc}
\hline & & Penggunaan Sumber-sumber sejarah \\
\hline Gaya & Pearson Correlation & $0.82^{* *}$ \\
Pembelajaran & Sig & 0.00 \\
& $\mathrm{~N}$ & 521 \\
\hline
\end{tabular}

** Correlation is significant at the 0.05 level

\section{Terdapat Hubungan yang Signifikan Antara Gaya Pembelajaran dengan Pengetahuan Penggunaan Sumber-Sumber Sejarah}

Berdasarkan Jadual 3, dapatan kajian ini telah melaporkan bahawa nilai keofisien korelasi Pearson antara min gaya pembelajaran $[r=0.78, p=0.00]$ terhadap pengetahuan penggunaan sumber-sumber sejarah adalah signifikan. Oleh itu, terdapat hubungan linear positif yang amat tinggi secara signifikan antara min gaya pembelajaran terhadap pengetahuan penggunaan sumber-sumber sejarah. Maka, $\mathrm{H}_{\mathrm{ola}}$ telah berjaya ditolak. Justeru, terdapat hubungan yang signifikan antara min gaya pembelajaran terhadap pengetahuan penggunaan sumber-sumber sejarah dalam kalangan murid. Perkara ini menerangkan bahawa sekiranya kecenderungan gaya pembelajaran adalah tinggi dalam kalangan murid, maka pengetahuan penggunaan sumber-sumber sejarah dalam kalangan murid juga adalah tinggi.

Jadual 2: Korelasi Gaya Pembelajaran dengan Pengetahuan Penggunaan SumberSumber Sejarah

\begin{tabular}{llc}
\hline & & Penggunaan Sumber-sumber sejarah (Pengetahuan) \\
\hline Gaya & Pearson Correlation & $0.78^{* *}$ \\
Pembelajaran & Sig & 0.00 \\
& $\mathrm{~N}$ & 521 \\
\hline
\end{tabular}

** Correlation is significant at the 0.05 level

Terdapat Hubungan yang Signifikan Antara Gaya Pembelajaran dengan Kemahiran Penggunaan Sumber-Sumber Sejarah

Berdasarkan Jadual 4, dapatan kajian ini telah melaporkan bahawa nilai keofisien korelasi Pearson antara min gaya pembelajaran $[r=0.77, p=0.00]$ terhadap kemahiran penggunaan sumber-sumber sejarah adalah signifikan. Oleh itu, terdapat hubungan linear positif yang amat tinggi secara signifikan antara min gaya pembelajaran terhadap kemahiran penggunaan sumber-sumber sejarah. Maka, $\mathrm{H}_{\mathrm{olb}}$ telah berjaya ditolak. Justeru, terdapat hubungan yang signifikan antara min gaya pembelajaran terhadap kemahiran penggunaan sumber-sumber sejarah dalam kalangan murid. Perkara ini menerangkan bahawa sekiranya kecenderungan gaya pembelajaran adalah tinggi dalam kalangan murid, maka kemahiran penggunaan sumber-sumber sejarah dalam kalangan murid juga adalah tinggi. 
Jadual 3: Korelasi Gaya Pembelajaran dengan Kemahiran Penggunaan SumberSumber Sejarah

\begin{tabular}{llc}
\hline & & Penggunaan Sumber-sumber sejarah (Kemahiran) \\
\hline Gaya & Pearson Correlation & $0.77^{* *}$ \\
Pembelajaran & Sig & 0.00 \\
& $N$ & 521 \\
\hline
\end{tabular}

** Correlation is significant at the 0.05 level

\section{Terdapat Hubungan yang Signifikan Antara Gaya Pembelajaran dengan Sikap Penggunaan Sumber-Sumber Sejarah}

Berdasarkan Jadual 5, dapatan kajian ini telah melaporkan bahawa nilai keofisien korelasi Pearson antara min gaya pembelajaran $[r=0.82, p=0.00]$ terhadap sikap penggunaan sumbersumber sejarah adalah signifikan. Oleh itu, terdapat hubungan linear positif yang amat tinggi secara signifikan antara min gaya pembelajaran terhadap sikap penggunaan sumber-sumber sejarah. Maka, $\mathrm{H}_{\mathrm{olc}}$ telah berjaya ditolak. Justeru, terdapat hubungan yang signifikan antara min gaya pembelajaran terhadap sikap penggunaan sumber-sumber sejarah dalam kalangan murid. Perkara ini menerangkan bahawa sekiranya kecenderungan gaya pembelajaran adalah tinggi dalam kalangan murid, maka sikap penggunaan sumber-sumber sejarah dalam kalangan murid juga adalah tinggi.

\section{Jadual 4: Korelasi Gaya Pembelajaran dengan Sikap Penggunaan Sumber-Sumber} Sejarah

\begin{tabular}{llc}
\hline & & Penggunaan Sumber-sumber sejarah (Sikap) \\
\hline Gaya & Pearson Correlation & $0.82^{* *}$ \\
Pembelajaran & Sig & 0.00 \\
& $\mathrm{~N}$ & 521 \\
\hline
\end{tabular}

** Correlation is significant at the 0.05 level

\section{Soalan Kajian 2}

\section{Sumbangan Pembolehubah Peramal dengan Penggunaan Sumber-Sumber Sejarah}

Berdasarkan Jadual 5 dan Jadual 6 menunjukkan bahawa pembolehubah gaya pembelajaran menyumbang secara signifikan terhadap penggunaan sumber-sumber sejarah $[F(6$, $514)=184.36, p=0.00]$. Justeru, gaya pembelajaran dilaporkan telah menyumbang hanya sebanyak 68 peratus varians terhadap penggunaan sumber-sumber sejarah $\left(r^{2}=0.68\right)$ yang menunjukkan terdapat kesan saiz yang sederhana (Cohen, 1988). Dari segi jenis gaya pembelajaran, gaya bersendirian merupakan pembolehubah peramal yang tertinggi $(\beta=0.26$, $t=5.52, p=0.00)$, diikuti dengan pembolehubah gaya visual $(\beta=0.22, t=4.33, p=0.00)$, pembolehubah gaya berkumpulan $(\beta=0.20, t=4.14, p=0.00)$ dan gaya auditori $(\beta=0.16, t=3.18$, $p=0.00)$ secara signifikan terhadap penggunaan sumber-sumber sejarah. Namun begitu, pembolehubah gaya taktil $(\beta=0.04, t=0.70, p=0.49)$ dan gaya kinestetik $(\beta=0.02, t=0.42$, $p=0.67)$ merupakan penyumbang kepada penggunaan sumber-sumber sejarah secara tidak signifikan. Justeru, dapat dirumuskan bahawa nilai $(\beta)$ bagi setiap unit peningkatan dalam pembolehubah tidak bersandar adalah diikuti dengan setiap unit peningkatan dalam pembolehubah bersandar. Nilai pekali pada Jadual 5 dan 6 juga telah menunjukkan bahawa terdapat hubungan linear bagi model dengan persamaan garis lurus bagi penggunaan sumbersumber sejarah dengan pemboleh ubah peramal adalah seperti berikut: 
di mana

$$
\begin{gathered}
\mathrm{Y}=\mathrm{A}+\mathrm{B}_{1 \mathrm{X} 1}+\mathrm{B}_{2 \mathrm{X} 2}+\mathrm{B}_{3 \mathrm{X} 3}+\mathrm{B}_{4} \mathrm{X} 4+\mathrm{e} \\
{[\mathrm{Y}=1.21+0.26 \mathrm{X} 1+0.22 \mathrm{X} 2+0.20 \mathrm{X} 3+0.16 \mathrm{X} 4+0.10]}
\end{gathered}
$$

$\mathrm{y}=$ Penggunaan sumber-sumber sejarah

$\mathrm{A}=$ pemalar

$\mathrm{B}_{1}, \mathrm{~B}_{2}, \mathrm{~B}_{3}, \mathrm{~B}_{4}=$ pekali

$\mathrm{X} 1=$ gaya bersendirian

$\mathrm{x} 2$ = gaya visual

$\mathrm{x} 3$ = gaya berkumpulan

$\mathrm{x} 3$ = gaya auditori

$\mathrm{e}=$ ralat kajian

Jadual 5: Analisis Varians Regresi Pelbagai

\begin{tabular}{lccccc}
\hline \multicolumn{1}{c}{ Pembolehubah } & $\begin{array}{c}\text { Jumlah kuasa } \\
\text { dua }\end{array}$ & $d f$ & $\begin{array}{c}\text { Min kuasa } \\
\text { dua }\end{array}$ & $F$ & Sig. \\
\hline Regresi & 330.82 & 6 & 55.14 & 184.36 & 0.00 \\
Reja & 153.72 & 514 & 0.30 & & \\
Jumlah & 484.53 & 520 & & & \\
\hline
\end{tabular}

Jadual 6: Analisis Regresi Pelbagai bagi Penggunaan Sumber-Sumber Sejarah dengan Pembolehubah Peramal

\begin{tabular}{lccccc}
\hline \multicolumn{1}{c}{ Pembolehubah } & $\begin{array}{c}\text { Pekali tidak piawai } \\
(\mathrm{B})\end{array}$ & $\begin{array}{c}\text { Ralat } \\
\text { pekali }\end{array}$ & Pekali Piawai $(\beta)$ & $t$ & Sig. \\
\hline Pemalar & 1.21 & 0.10 & & 12.21 & 0.00 \\
Gaya visual & 0.04 & 0.01 & 0.22 & 4.33 & 0.00 \\
Gaya auditori & 0.03 & 0.01 & 0.16 & 3.18 & 0.00 \\
Gaya taktil & 0.01 & 0.01 & 0.04 & 0.70 & 0.49 \\
Gaya kinestetik & 0.01 & 0.01 & 0.02 & 0.42 & 0.67 \\
Gaya Bersendirian & 0.04 & 0.01 & 0.26 & 5.52 & 0.00 \\
Gaya Berkumpulan & 0.03 & 0.01 & 0.21 & 4.14 & 0.00 \\
\hline
\end{tabular}

\section{Perbincangan Kajian}

Dapatan kajian ini telah menunjukkan bahawa terdapat hubungan linear positif yang amat tinggi secara signifikan antara gaya pembelajaran dengan penggunaan sumber-sumber sejarah dari aspek pengetahuan, kemahiran dan sikap. Dapatan ini adalah bertepatan dengan sumber sejarah dan belajar cara belajar antara dua perkara yang perlu diberi perhatian semasa proses pengajaran dalam kurikulum sejarah. Hal ini kerana pembelajaran sejarah yang melibatkan penggunaan bahan-bahan yang tertentu dalam mengkaji sesuatu maklumat sejarah adalah berbeza mengikut cara dan gaya murid disebabkan oleh pengingtegrasian kaedah pengajaran dan persekitaran pembelajaran yang tertentu (PPK, 2003; Dunn \& Dunn, 1978). Oleh kerana terdapat murid-murid yang suka belajar dengan dibantu oleh bahan-bahan tertentu mahupun murid-murid yang suka belajar secara berkumpulan atau bersendirian di dalam kelas, maka secara tidak langsung ianya didapati akan mempengaruhi pencapaian murid (Suppiah et al, 2009). Perkara ini adalah selaras dengan dapatan kajian Kaviza, (2018b) yang mendapati bahawa penggunaan sumber-sumber sejarah telah dibuktikan mempengaruhi pencapaian mata pelajaran sejarah. Tambahan pula, Lee, (2002) dan Mohd Fauzi Ali, Abdul Razaq Ahmad dan Ahmad Ali Seman, (2017) dalam kajiannya yang telah menjelaskan bahawa kompetensi guruguru sejarah dalam mengintegrasikan bahan pembelajaran tertentu, khususnya sumber-sumber sejarah yang sesuai dengan kecerdasan dan kebolehan murid dapat meningkatkan pencapaian murid adalah menyokong dapatan kajian ini. Selain itu, gaya berkumpulan, gaya visual, gaya 
bersendirian dan gaya auditori yang didapati menyumbang secara signifikan terhadap penggunaan sumber-sumber sejarah dalam kajian ini adalah selari dengan gaya kecenderungan yang diamalkan oleh murid-murid yang mengambil mata pelajaran sejarah di sekolah menengah iaitu gaya auditori dan gaya berkumpulan seperti dilaporkan dalam kajian Kaviza, (2019). Hal ini kerana cara belajar murid yang lebih suka untuk mendengar maklumat sejarah dan belajar dalam bentuk aktiviti perbincangan dengan rakan-rakan mempunyai kaitan dengan penggunaan bahan dan alat bantu mengajar yang digunakan oleh guru-guru di dalam kelas. Penggunaan sumber-sumber sejarah dalam bentuk tulisan ataupun dalam bentuk paparan dapat membentuk kecenderungan pembelajaran yang pelbagai dalam kalangan murid. Pendapat ini adalah selari dengan pendapat Anuar Ahmad, Siti Haishah Abdul Rahim dan Nur Atiqah T.Abdullah, (2009), Azwan Ahmad, Abdul Ghani Kaneson Abdullah, Mohammad Zohir Ahmad dan Abdul Rahman Abdul Aziz, (2005) dan Mohd Johdi Salleh dan Ariegusrini Agus, (2009) yang menjelaskan bahawa perubahan dalam stail dan efikasi pengajaran guru sejarah dengan menggunakan bahan-bahan pembelajaran tertentu dapat menyediakan persekitaran pengajaran dan pembelajaran yang lebih menarik.

\section{Kesimpulan}

Oleh kerana gaya pembelajaran murid dan penggunaan sumber-sumber sejarah didapati mempunyai hubungan linear positif yang amat tinggi secara signifikan, maka implikasi kajian ini telah mencadangkan kepada guru-guru sejarah untuk memberikan penekanan utama terhadap aspek gaya pembelajaran murid yang didapati mempengaruhi penggunaan sumbersumber sejarah secara langsung dan ianya adalah selaras dengan saranan dalam kurikulum sejarah yang menekankan kepada elemen sumber sejarah dan belajar cara belajar semasa merancang dan melaksanakan proses pengajaran dan pembelajaran sejarah (PPK, 2003). Hal ini kerana perbezaan cara belajar dapat menentukan peningkatan pengetahuan, kemahiran serta sikap mereka terhadap penggunaan sumber-sumber sejarah dalam kalangan murid. Oleh itu, guru-guru sejarah perlu peka terhadap gaya dan perlakuan setiap murid di dalam kelasnya sebelum sumber-sumber sejarah didedahkan dalam proses pengajaran dan pembelajaran agar pencapaian akademik dapat dipertingkatkan secara berterusan.

\section{Rujukan}

Anuar Ahmad, Siti Haishah Abdul Rahim \& Nur Atiqah T.Abdullah. (2009). Tahap Keupayaan Pengajaran Guru Sejarah dan Hubungannya dengan Pencapaian Murid Berprestasi Rendah. Jurnal Pendidikan Malaysia, 34(1), 53-66.

Azwan Ahmad, Abdul Ghani Kaneson Abdullah, Mohammad Zohir Ahmad \& Abdul Rahman Abdul Aziz. (2005). Kesan Efikasi Guru Sejarah terhadap Amalan Pengajaran Berbantukan Teknologi Maklumat dan Komunikasi (TMK). Jurnal Penyelidikan Pendidikan, 7, 14-26.

Cohen, J. (1988). Statistical Power Analysis for the Behavioral Sciences. New York: Routledge Academic.

Creswell, J. W. (2014). Educational Research: Planning, Conducting and Evaluating Quantitative and Qualitative Research ( $4^{\text {th }}$ Ed). New Jersey: Pearson Prentice Hall.

Curry, L. (1983). An Organization of Learning Style Theory and Construct. Kertas kerja yang dibentangkan di Annual Meeting of the American Educational Research Association $67^{\text {th }}$ Montreal, Quebec, April 11-15 1983.

Davies, J. A. (1971). Elementary Survey Analysis. New Jersey: Prentice Hall.

Dunn, R., \& Dunn, K. 91978). Teaching Students through their individual learning styles. Reston: Reston. 
Dutt-Doner, K., Cook-Cottone, C., \& Alien, S. (2007). Improving classroom instruction: Understanding the developmental nature of analyzing primary sources. Research in Middle Level Education, 30(6), 1-20.

Greene, S. (1994). The problems of learning to think like a historian. Writing history in the culture of the classroom. Educational Psychologist, 29(2), 89-96.

Hazri Jamil. (2003). Teknik mengajar Sejarah. Pahang: PTS Publications \& Distributors Sdn Bhd.

Hover, S.V., Hicks, D., \& Dack, H. (2016). From Source to Evidence? Teachers' Use of Historical Sources in Their Classrooms. The Social studies, 107(6), 209-217.

Johansson, P. (2017). Learning study as a clinical research practice to generate knowledge about the learning of historical primary source analysis. Educational Action Research, $25(1), 167-181$.

Kaviza, M. (2019). Kecenderungan Gaya Pembelajaran Murid dalam Mata Pelajaran Sejarah: Satu Kajian Awal. Malaysian Journal of Social Sciences and Humanities, 4(1), 82-90.

Kaviza, M. (2018a). Pengetahuan, Kemahiran dan Sikap Terhadap Penggunaan Sumber Sejarah di sekolah Menengah: Perspektif Murid. Prosiding Seminar Kebangsaan Majlis Dekan Pendidikan Universiti Awam 2018, 11-22.

Kaviza, M. (2018b). Hubungan antara Pengetahuan, Kemahiran dan Sikap dalam Penggunaan Sumber-sumber Sejarah terhadap Pencapaian Mata Pelajaran Sejarah. Prosiding Seminar Darulaman 2018 Peringkat Kebangsaan, 481-487.

Lee, J. (2002). Digital History in the History / Social Studies Classroom. The History Teacher, 35(40), 503-517.

Lee, J.K., Doolittle, P.E., \& Hicks, D. (2006). Social studies and history teacher's uses of non-digital and digital historical resources. Social studies Research and Practice, 1(3), 291-311.

McLaughlin, C. (1999). The Implications of Research Literature on Learning Styles for the design of instructional material. Australian Journal of Educational Technology, 15(3), 222-241.

Mohd Fauzi Ali, Abdul Razaq Ahmad \& Ahmad Ali Seman. (2017). Teachers competences in teaching and learning history. Open Journal of Social Sciences, 220-228.

Mohd Johdi Salleh \& Ariegusrini Agus. (2009). Transformasi Pengajaran dan Pembelajaran Sejarah. Bangi: Universiti Kebangsaan Malaysia. Retrieved from: http://irep.iium.edu.my

Patterson, N.C., Lucas, A.G., \& Kithinji, M. (2012). Higher Order Thinking in Social Studies: An analysis of Primary Source Document Use. Social studies Research and Practice, 7(2), 68-85.

Pusat Perkembangan Kurikulum. (2003) Huraian Sukatan Pelajaran Sejarah Tingkatan Empat. Putrajaya: Kementerian Pendidikan Malaysia.

Reid, J. (1984). Perceptual Learning Style Preferences of ESL Students. TESOL Quarterly, $21,87-111$

Reisman, A., \& Fogo, B. (2016). Contributions of Educative document based curricular materials to quality of historical instruction. Teaching and Teacher Education, 59, 191-202.

Suppiah Nachiappan, Kamarulzaman Kamaruddin, Abdul Aziz Abdul Shukor, Ramlah Jantan, Roslinda Mustapha \& Hazalizah Hamzah. (2009). Pembelajaran dan Perkembangan Pelajar. Shah Alam: Oxford Fajar Sdn Bhd

Wiley, J. \& Voss, J.F. (1999). Constructing arguments from multiple sources: Tasks that promote understanding and not just memory for text. Journal of Educational Psychology, 91(2), 301-311 
Wineburg, S.S (1991). On the reading of historical text: Notes on the Breach between School and Academy. American Educational Research Journal, 28(3), 495-519. 